\title{
IMPROVEMENTS IN THE UPPER BOUNDS FOR THE SPREAD OF A MATRIX
}

\author{
PINGPING ZHANG AND HU YANG
}

Abstract. In this paper, we present some new upper bounds for the spread of a matrix. These bounds improve the previous results. In addition, one of these bounds can be up to the optimum. Finally, some numerical matrices are given to show the effectiveness of our results.

Mathematics subject classification (2010): 15A09, 15A18, 15A45, 65F35. value.

Keywords and phrases: The spread of a matrix, upper bounds, singular matrix, improvement, eigen-

\section{REFERENCES}

[1] E. B. BARnes AND A. J. Hoffman, Bounds for the spectrum of normal matrices, Linear Algebra Appl, Vol. 201, 1 (1994), pp. 79-90.

[2] P. R. BEESACK, The spread of matrices and polynomials, Linear Algebra Appl, Vol. 31, 1 (1980), pp. $145-149$.

[3] E. Deutsch, On the spread of matrices and polynomials, Linear Algebra Appl, Vol. 22, 1 (1978), pp. 49-55.

[4] R. DRNOVŠEK, The spread of the spectrum of a nonnegative matrix with a zero diagonal element, Linear Algebra Appl, Vol. 439, 8 (2013), pp. 2381-2387.

[5] R. KRess And H. L. D. VRIES, On nonnormal matrices, Linear Algebra Appl, Vol. 8, 2 (1974), pp. $109-120$

[6] J. K. Merikoski And R. Kumar, Characterizations and lower bounds for the spread of a normal matrix, Linear Algebra Appl, Vol. 364, 1 (2003), pp. 13-31.

[7] L. Mirsky, Inequalities for normal and Hermitian matrices, Duke Math. J., Vol. 24, 4 (1957), pp. 591-599.

[8] L. MiRs Ky, The spread of a matrix, Mathematika, Vol. 3, 2 (1956), pp. 127-130.

[9] P. Nowos AD AND R. Tovar, Spectral inequalities and $G$-functions, Linear Algebra Appl, Vol. 31, 1 (1980), pp. 179-197.

[10] R. SHARMA AND R. KUmAR, Remark on upper bounds for the spread of a matrix, Linear Algebra Appl, Vol. 438, 11 (2013), pp. 4359-4362.

[11] B. Tu, On the spread of a matrix, Journal of Fudan University (Natural Science) (in Chinese), Vol. 23, 4 (1984), pp. 435-441.

[12] J. L. WU, P. P. ZhaNG AND W. S. LiAO, Upper bounds for the spread of a matrix, Linear Algebra Appl, Vol. 437, 11 (2012), pp. 2813-2822. 